Özgen, I. ; Teuber, K. ; Simons, F.; Liang, D. ; Hinkelmann, R.

\title{
Upscaling the shallow water model with a novel roughness formulation
}

Journal article | Accepted manuscript (Postprint)

This version is available at http://dx.doi.org/10.14279/depositonce-7230

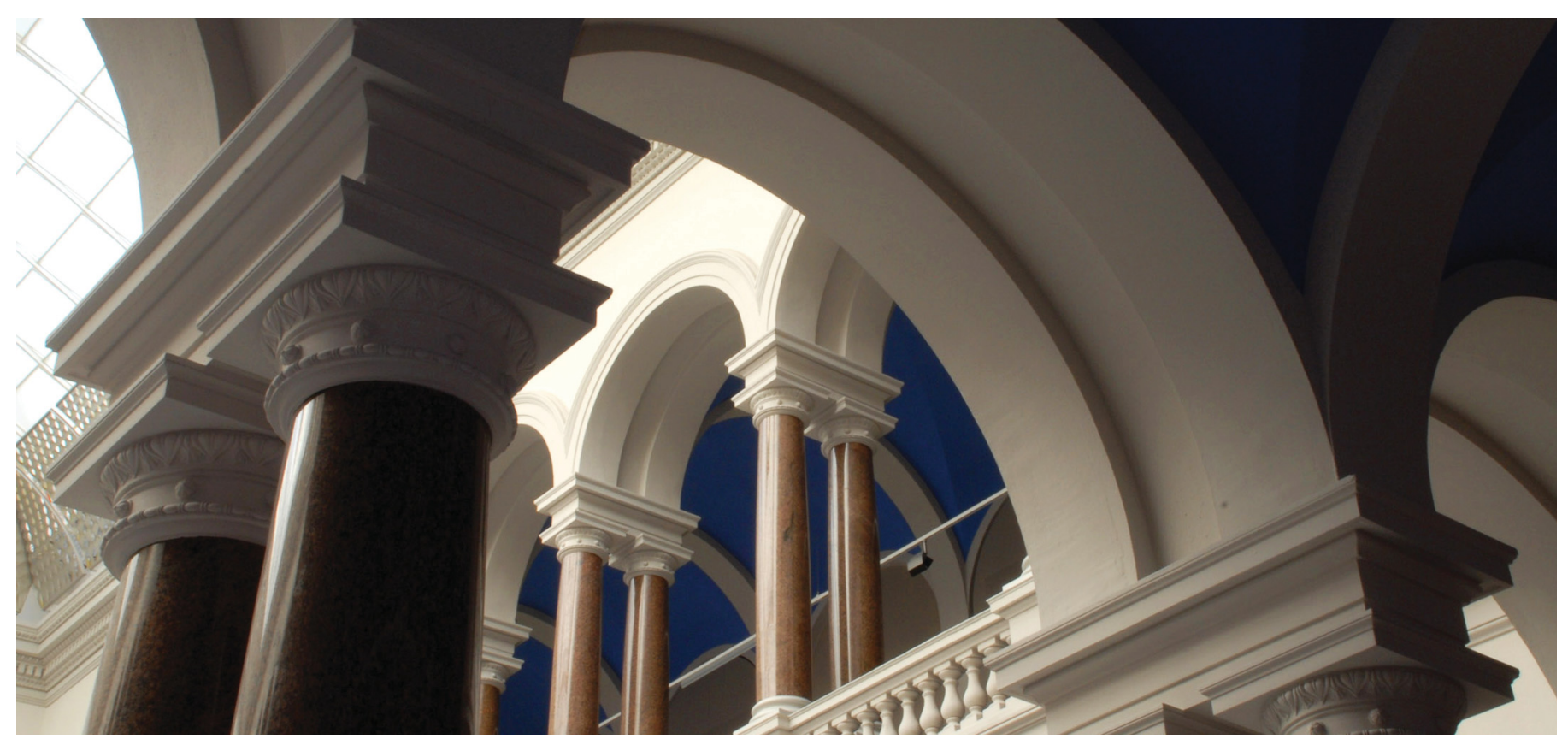

This is a post-peer-review, pre-copyedit version of an article published in Environmental Earth Sciences.

The final authenticated version is available online at: https://doi.org/10.1007/s12665-015-4726-7

Özgen, I., Teuber, K., Simons, F., Liang, D., \& Hinkelmann, R. (2015). Upscaling the shallow water model with a novel roughness formulation. Environmental Earth Sciences, 74(11), 7371-7386.

https://doi.org/10.1007/s12665-015-4726-7 


\title{
Upscaling the shallow water model with a novel roughness formulation
}

\author{
Ilhan Özgen ${ }^{1}$ Katharina Teuber ${ }^{1}$ Franz Simons ${ }^{2}$ Dongfang Liang ${ }^{3}$ Reinhard Hinkelmann ${ }^{1}$
}

\begin{abstract}
This study presents a novel roughness formulation to conceptually account for microtopography and compares it to four existing roughness models from literature. The aim is to increase the grid size for computational efficiency, while capturing subgrid scale effects with the roughness formulation to prevent the loss in accuracy associated with coarse grids. All roughness approaches are implemented in the Hydroinformatics Modeling System and compared with results of a high resolution shallow water model in three test cases: rainfall-runoff on an inclined plane with sine-wave shaped microtopography, flow over an inclined plane with random microtopography and rainfall-runoff in a small natural catchment. Although the high resolution results can not be reproduced exactly by the coarse grid model, e.g. local details of flow processes can not be resolved, overall good agreement between the upscaled models and the high resolution model has been achieved. It is concluded that the accuracy increases with the number of calibration parameters available, however the calibration process becomes more difficult. Using coarser grids results in significant speedup in comparison with the high resolution simulation. In the presented test cases the speedup varies from 20 up to 2520 , depending on the size and complexity
\end{abstract}

Corresponding author: Ilhan Özgen

ilhan.oezgen@wahyd.tu-berlin.de

(1) Chair of Water Resources Management and Modeling of Hydrosystems, Technische Universität Berlin, Secr. TIB1-B14, Gustav-Meyer-Allee 25, 13355 Berlin, Germany

(2) Bundesanstalt für Wasserbau, Kußmaulstraße 17, 76187 Karlsruhe, Germany

(3) Department of Engineering, University of Cambridge, Trumpington Street, Cambridge CB2 1 PZ, UK of the test case and the difference in cell sizes. The proposed roughness formulation generally shows the best agreement with the reference solution, compared to the other models investigated in this study.

Keywords Upscaling · Roughness formulation - Shallow water equations · Overland flow

\section{Introduction}

Recent developments in survey technology such as light detection and ranging (LIDAR) and laser scanning are able to provide high-resolution elevation data sets, e.g. in $\mathrm{Fu}$ et al. (2015), Zhao et al. (2015), Pradhan and Kim (2015), yet the integration of these data into numerical models is often challenging because of finite computer resources (Gourbesville 2009; McMillan and Brasington 2007; Dottori et al. 2013). The use of high-resolution elevation data is generally desirable, because it allows a better representation of spatial heterogeneity and localized flow processes. However, high-resolution simulations of practical interest, e.g. across catchment or city scales, are often unfeasible without supercomputers because they are computationally very demanding (Smith and Liang 2013; Lacasta et al. 2015). Therefore, high-resolution elevation data is usually averaged over relatively coarse grid cells (Jain and Singh 2005) which results in loss of model accuracy ( $Y u$ and Lane 2006).

The accuracy of coarse grid models can be improved by conceptually accounting for subgrid-scale effects by calibrating the roughness coefficient (Néelz and Pender 2007). This is a valid natural approach because by definition, a roughness coefficient expresses a parameterization of subgrid topography (Smith 2014). In principle, the 
roughness coefficient in shallow water models represents the shear stress at the bottom of a water column but it is often used to account for all unresolved processes, e.g. turbulence, depth-averaging effects, and therefore may lose its physical meaning (Morvan et al. 2008). The value of the calibrated roughness coefficient is usually heavily dependent on the calibration conditions, e.g. water depth, grid size, and can not be transferred easily to different conditions (Hughes et al. 2011; Yörük 2009).

Upscaling is the approximation of a system of partial differential equations by another system of partial differential equations that can be solved with fewer computing resources (Farmer 2002). The upscaling process usually requires the determination of a set of coefficients, which conceptually account for properties of the original system. The main advantage of using roughness formulations instead of more sophisticated upscaling approaches for shallow water models, e.g. Guinot and Soares-Frazão (2006), Volp et al. (2013), Hughes et al. (2011), McMillan and Brasington (2007), Liang et al. (2007), is their easy implementation into existing models without the need to modifiy the governing equations or numerical methods.

This study presents a novel roughness formulation to account for the effects of microtopography and investigates limits and capabilities of upscaling shallow water equations based overland flow models using roughness formulations. The proposed new formulation uses the experimental studies in Lawrence (1997), Souchere et al. (1998), Tsihrintzis et al. (2001) as theoretical basis and is to some extent inspired by the roughness models in Razafison et al. (2012), Jain and Kothyari (2004). The distribution function of the subgrid-scale bottom elevation and the water depth are used to calculate a dimensionless inundation ratio, which is then used to calculate a roughness coefficient. Further, the bottom slope is taken into account. The formulation is compared with four different roughness models: Manning's model with constant roughness coefficient; Lawrence's model (1997); Manning's model with a waterdepth dependent roughness coefficient (Mügler et al. 2011) and Razafison's furrow roughness model (Razafison et al. 2012). All approaches are implemented in the Hydroinformatics Modeling System (hms), which is an in-house cell-centered finite-volume code developed at the Chair of Water Resources and Modeling of Hydrosystems, Technische Universität Berlin (Simons et al. 2014). Three test cases are presented to evaluate the proposed approach: rainfall-runoff on an inclined plane with sine-wave shaped microtopography; surface flow over an inclined plane with random microtopography; and rainfall-runoff in a small Alpine catchment.

\section{Governing equations}

\section{Shallow water equations}

The depth-averaged shallow water equations can be written in a conservative form as:

$$
\frac{\partial \mathbf{q}}{\partial t}+\frac{\partial \mathbf{f}}{\partial x}+\frac{\partial \mathbf{g}}{\partial y}=\mathbf{S}
$$

where $t$ is time, $x$ and $y$ are the Cartesian coordinates, $\mathbf{q}, \mathbf{f} \mathbf{g}$ and denote the vectors of conserved flow variables, fluxes in the $x$ - and $y$-directions, respectively. $\mathbf{S}$ is the source vector including bed slope source $\mathbf{S}_{\mathbf{b}}$ and friction source term $\mathbf{S}_{\mathbf{f}} . \mathbf{q}, \mathbf{f}$ and $\mathbf{g}$ are usually expressed as:

$$
\mathbf{q}=\left[\begin{array}{c}
\mathbf{h} \\
\mathbf{q}_{\mathbf{x}} \\
\mathbf{q}_{\mathbf{y}}
\end{array}\right], \quad \mathbf{f}=\left[\begin{array}{c}
\mathbf{q}_{\mathbf{x}} \\
\mathbf{u} \mathbf{q}_{\mathbf{x}}+\mathbf{0 . 5} \mathbf{g h}^{2} \\
\mathbf{u} \mathbf{q}_{\mathbf{y}}
\end{array}\right], \quad \mathbf{g}=\left[\begin{array}{c}
\mathbf{q}_{\mathbf{y}} \\
\mathbf{v q _ { \mathbf { x } }} \\
\mathbf{v q _ { \mathbf { y } }}+\mathbf{0 . 5} \mathbf{g h}^{2}
\end{array}\right] .
$$

Here, $h, u, v$ are the water depth and depth-averaged velocity in $x$ - and $y$-directions, respectively; $q_{x}$ and $q_{y}$ are the unit-width discharges in $x$ - and $y$-directions, and $q_{x}=u h, q_{y}=v h ; g$ represents the gravity acceleration. The source vector $\mathbf{S}$ can be split into

$$
\mathbf{S}=\mathbf{S}_{\mathbf{b}}+\mathbf{S}_{\mathbf{f}}+\mathbf{S}_{\mathbf{o}}
$$

Here $\mathbf{S}_{\mathbf{0}}$ accounts for additional source terms, e.g. rainfall, wind shear on the free surface, Coriolis-force. It is noted that the first entry of the vector $\mathbf{S}$ is the mass source, the second entry and third entry are momentum source terms in $x$ - and $y$-direction, respectively. Writing out the vectors leads to:

$$
\begin{aligned}
& \mathbf{S}=\left[\begin{array}{c}
\mathbf{0} \\
\mathbf{s}_{\mathbf{b}, \mathbf{x}} \\
\mathbf{s}_{\mathbf{b}, \mathbf{y}}
\end{array}\right]+\left[\begin{array}{c}
\mathbf{0} \\
\mathbf{s}_{\mathbf{f}, \mathbf{x}} \\
\mathbf{s}_{\mathbf{f}, \mathbf{y}}
\end{array}\right]+\left[\begin{array}{c}
\mathbf{i} \\
\mathbf{0} \\
\mathbf{0}
\end{array}\right], \\
& \mathbf{S}=\left[\begin{array}{c}
\mathbf{0} \\
-\mathbf{g h} \partial \mathbf{z}_{\mathbf{b}} / \partial \mathbf{x} \\
-\mathbf{g h} \partial \mathbf{z}_{\mathbf{b}} / \partial \mathbf{y}
\end{array}\right]+\left[\begin{array}{c}
\mathbf{0} \\
-\mathbf{g u}|\mathbf{v}| / \mathbf{C}^{2} \\
-\mathbf{g v}|\mathbf{v}| / \mathbf{C}^{2}
\end{array}\right]+\left[\begin{array}{l}
\mathbf{i} \\
\mathbf{0} \\
\mathbf{0}
\end{array}\right] .
\end{aligned}
$$

$z_{b}$ stands for bottom elevation; $\mathbf{v}=\{\mathbf{u}, \mathbf{v}\}$ is the vector of velocity; $|\cdot|$ denotes the vector norm and $C$ is the so-called Chézy coefficient accounting for flow resistance and $i$ is the rainfall intensity. As shown in, e.g. Simons et al. (2014), Smith et al. (2007), every friction law coefficient can be transformed into the Chézy coefficient and therefore can be incorporated in Eq. 1. Viscosity of the fluid, turbulence, wind shear stress on the free surface and Coriolis-force are neglected in this study. The incorporation of these effects into the shallow water equations can be found in, e.g. Hinkelmann (2005). 


\section{Existing roughness formulations}

Friction laws can be written in a generalized form as:

$\mathbf{S}_{\mathbf{f}}=-\mathbf{K h}^{\alpha}|\mathbf{v}|^{\beta} \mathbf{v}$

where $\alpha$ and $\beta$ are positive real numbers and $K$ is the proportionality constant. Well known friction laws such as, e.g. Manning's law and the Darcy-Weisbach law, can be obtained by a certain choice for $\alpha$ and $\beta$. When formulating a friction law, the choice of $\alpha$ and $\beta$ is arbitrary (Razafison et al. 2012), however the choice is usually related to experimental data sets.

Manning's law with constant roughness can be obtained by choosing $\alpha=-1 / 3$ and $\beta=1$ in Eq. 6 :

$\mathbf{S}_{\mathbf{f}}=-\mathbf{g} \mathbf{n}^{2} \mathbf{h}^{-1 / 3}|\mathbf{v}| \mathbf{v}$

Here, $n$ is the Manning roughness coefficient, which relates to the Chézy coefficient as:

$C=\frac{h^{1 / 6}}{n}$.

In Lawrence's roughness model (Lawrence 1997), different flow regimes associated with different roughness formulations are identified for different inundation ratios. The inundation ratio $\lambda$ is calculated as:

$\Lambda=\frac{h}{k}$

by using a characteristic roughness length $k$, which is identified as the mean grain size of the river bed. For increasing $\lambda$, the influence of the subgrid-scale topography decreases. The frictional resistance $f$ is calculated for $\Lambda<1$ with a drag force approach

$f=\frac{8 \phi C_{d}}{\pi} \min \left(\frac{\pi}{4}, \Lambda\right)$

where $C_{d}$ stands for the drag coefficient for roughness elements, and $\phi$ is the fraction of the surface covered by roughness elements. For the drag coefficient, $C_{d}=1$ is assumed (Lawrence 1997). The operator $\min (\cdot)$ is the minimum function, which outputs the smallest value of all input values. For $1 \leq \Lambda \leq 10$, a power law in the form of:

$f=\frac{10}{\Lambda^{2}}$

is suggested. For $\Lambda>10, f$ is calculated with:

$f=\frac{1}{(1.64+0.803 \ln \Lambda)^{2}}$.

The suggested calibration parameters of this model are $\phi$ (cf. Eq. 10) and $k$ (cf. Eq. 9) Mügler et al. (2011). $f$ can be transformed into the Chézy coefficient by using:

$$
C=\sqrt{\frac{8 g}{f}}
$$

The depth-dependent variable Manning's coefficient has been developed for rainfall-runoff models in Jain and Kothyari (2004) and is calculated as follows:

$n(h)=\left\{\begin{array}{lll}n_{0}\left(\frac{h}{h_{0}}\right)^{-\epsilon} & \text { for } & h<h_{0}, \\ n_{0} & \text { for } \quad h \geq h_{0}\end{array}\right.$

In this model, $n_{0}$ is defined as the Manning's roughness occuring at flow depth $h_{0}$ beyond which $n$ is assumed constant and $\epsilon$ is a parameter accounting for vegetation. The transformation into the Chézy coefficient is done according to Eq. 8. The variable Manning's coefficient model has three calibration parameters: $n_{0}, h_{0}$ and $\epsilon$.

Finally, a roughness formulation to account for unresolved furrows is derived by Razafison et al. in (2012). Here, Eq. 6 is rewritten as:

$\mathbf{S}_{\mathbf{f}}=-\mathbf{g ~ n}^{2} \mathbf{h}^{-1 / 3}|\mathbf{v}| \mathbf{v}-K_{\mathrm{R}} \mathbf{h} \mathbf{v}$

where the first term is the classical Manning's equation and the second term is an additional friction term accounting for the furrows. The coefficient $K_{\mathrm{R}}$ in this model is calculated as follows:

$K_{\mathrm{R}}=K_{0, \mathrm{R}} \exp \left(\frac{-h+\left\langle h_{F}\right\rangle}{C \cdot\left\langle h_{F}\right\rangle}\right)$

Here, $K_{0, \mathrm{R}}$ and $C$ are unitless model parameters; and $\left\langle h_{F}\right\rangle$ is the average height of water trapped in furrows which may be calculated with

$$
\left\langle h_{F}\right\rangle=\frac{V}{L_{F} \cdot L},
$$

whereby $V$ is the volume of trapped water in a furrow, $L_{F}$ is its wavelength and $L$ is the length of the domain. Razafison suggests to approximate $\left\langle h_{F}\right\rangle$ numerically (personal communication, August 4, 2014). The model is calibrated with $C$ and $K_{0, \mathrm{R}}$.

In summary, common roughness formulations usually express a relationship between water depth and roughness, often in the form of a power law, e.g. Mügler et al. (2011), Tsihrintzis et al. (2001), Jain and Kothyari (2004), Razafison et al. (2012). In the authors' opinion, a more general approach can be obtained for free surface flows by using the inundation ratio instead of the water depth and by including the unitless bottom slope into the formulation.

\section{Novel roughness formulation}

$\alpha=0$ and $\beta=1$ are chosen in Eq. 6, which allows to rewrite the friction source term in Eq. 5 as 
$\mathbf{S}_{\mathbf{f}}=-\left(\frac{\mathbf{g}}{\mathbf{C}_{\mathbf{0}}^{2}}+\mathbf{K}\right)|\mathbf{v}| \mathbf{v}$.

Here, subgrid-scale topography is accounted for with the parameter $K$ from Eq. 6 which is here interpreted as a variable dimensionless roughness value, which increases the roughness of the model in dependency of the inundation ratio, and the Chézy coefficient $C_{0}$. The index 0 implies that the value of $C_{0}$ differs from the value of the Chézy coefficient in the classical formulation of Eq. 5. $C_{0}$ is a model calibration parameter. In this study, a constant Manning formulation (Eq. 8) is used to calculate $C_{0}$.

Experimental results reported in Souchere et al. (1998) show that the bottom slope $I$ reduces the influence of tillage significantly. This findings certainly can be extended to microtopography in general, as increasing the slope is associated with a loss of surface storage (Thompson et al. 2010).

Equation 18 is required to satisfy the following requirements:

1. If $\Lambda$ increases, the influence of the subgrid-scale topography decreases significantly, hence $K$ should converge to 0 .

2. If $I$ increases, the influence of the subgrid-scale topography should decrease, hence $K$ should decrease.

3. For large $\Lambda$, only $C_{0}$ should account for subgrid-scale effects.

Based on preliminary numerical studies by the authors (Teuber 2015), the following formulation for $K$ is proposed, which satisfies these requirements:

$K=\alpha_{0} \exp \left(-\alpha_{1}(\Lambda-1)\right)$

Here, $\exp (\cdot)$ stands for the natural exponential function. The inundation ratio is calculated by a modified expression of Eq. 9 to take the effect of bottom slope into account:

$\Lambda=\frac{h}{(1-I) k}$

The inundation ratio has been used before in literature to derive friction laws, e.g. Lawrence (1997). It stands for the ratio of the water depth $h$ to the characteristic roughness length $k$. If the inundation ratio is smaller than 1 , the water depth is smaller than the characteristic roughness length, which indicates a partially dry area. in this case the flow will be influenced significantly by the subgrid-scale topography. Consequently, a high inundation ratio states that the water depth is relatively high when related to the characteristic roughness length and the flow will not be influenced strongly by the subgrid-scale topography. Both cases are illustrated in Fig. 1. The choice which value should be used as characteristic roughness is not trivial. Suggestions in literature range from standard deviation of elevations to grain size percentiles (Smith and Liang 2013). In this study, the standard deviation of microtopography, hereinafter referred to as $\sigma$, is used as the characteristic roughness length $k . \sigma$ represents a summary of topographic irregularity and is often used as a roughness indicating parameter (Smith et al. 2007; Smith 2014), hence it is reasonable to use it as the characteristic roughness length. The relationship between $\sigma$ and the maximum value of the distribution $a_{r}$ can be approximated by $a_{r}=2 \sigma$ (Defina 2000), which means that $\Lambda=1$ does not indicate full inundation but marks the point, where the majority of the subgrid-scale topography has been inundated. For the derivation of the depth-averaged shallow water equations, $I$ is required to be very small. In shallow water flow simulations, $I$ is usually in the range of $0-0.1$.

Equations 18, 19 and 20 together represent the proposed roughness formulation. To provide some physical interpretation on the calibration parameters, $\alpha_{0}$ can be regarded as a dimensionless friction coefficient. $\alpha_{1}$ can be interpreted as a geometric conveyance parameter. It accounts for the influence of the spatial distribution of the subgridscale elevations, e.g. blockade effects due to clustering mentioned in $\mathrm{Yu}$ and Lane (2006). A large $\alpha_{1}$ indicates that the conveyance of the spatial distribution is high, so $K$ decreases faster. In the applications presented in this work, $\alpha_{0}$ and $\alpha_{1}$ are model calibration parameters. Thus, in total three parameters are used for model calibration; $C_{0}, \alpha_{0}$, and $\alpha_{1}$. However, as $C_{0}$ is calculated via Eq. 8, the model is actually calibrated using a Manning's coefficient $n$.

Fig. 1 Illustration of the concept of the inundation ratio $\Lambda$
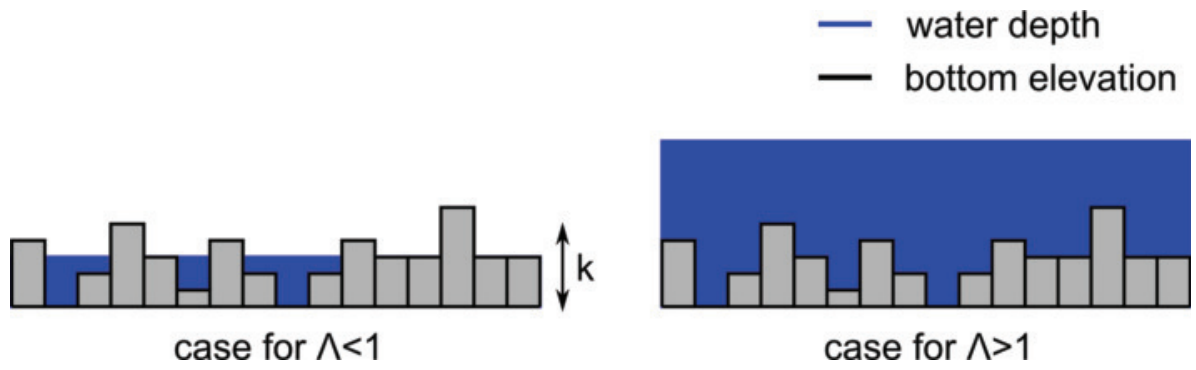


\section{Numerical implementation}

The shallow water equations, shown in Eq. 1, are discretized with cell-centered finite volumes. The discretized equations are solved numerically with a second order monotonic-upstream-centered scheme for conservation laws (MUSCL). The implementation is applicable to both structured and triangular meshes, however in this work structured grids with square-shaped cells were used. A brief overview of the implementation is given below. For more detailed information, the reader is referred to Simons et al. (2014).

\section{Interface flux calculation}

The fluxes at cell interfaces, given by the vectors $\mathbf{f}$ and $\mathbf{g}$ in Eq. 2, are functions of the state variables $h$ and v. Appropriate values for the state variables are calculated by solving the Riemann problem on the interface via a Harten, Lax and van Leer approximate Riemann solver with the contact wave restored (HLLC) (Toro et al. 1994). The Riemann states at the left and right side of the interface, namely $h_{L}, h_{R}$ and $\mathbf{v}_{\mathbf{L}}, \mathbf{v}_{\mathbf{R}}$ where $L$ and $R$ stand for the left and right side of the interface, respectively, are extrapolated from the cell center with a three-point-stencil with slope limiters, shown in Hou et al. (2012, 2013b). In this study, the min-mod limiter is used to suppress spurious oscillations.

To well preserve the C-property, non-negative hydrostatic reconstruction of the bottom elevation at the interface is used (Audusse et al. 2004). The water depth and bottom elevation are modified prior to the Riemann solution (Hou et al. 2013a). Discussion of the non-negative hydrostatic reconstruction method is given in Hou et al. (2014), Delestre et al. (2012).

\section{Slope and friction source term treatment}

The bottom slope source term $\mathbf{S}_{\mathbf{b}}$ of a cell (cf. Eq. 3) is transformed into fluxes through the cell faces (Hou et al. 2013a).

The friction source term is discretized with the splitting point-implicit method derived in Liang and Marche (2009), which allows a fully implicit integration of the friction source term.

In order to avoid numerical instabilites caused by too high friction source terms, the entries $s_{f, x}$ and $s_{f, y}$ of the vector $\mathbf{S}_{\mathbf{f}}$ (cf. Eq. 5) are limited as shown in Liang and Marche (2009):

$s_{f, i} \begin{cases}\geq-q_{i}^{n} \Delta t & \text { if } q_{i}^{n} \geq 0 \\ \leq-q_{i}^{n} \Delta t & \text { if } q_{i}^{n}<0\end{cases}$
Here, the subscript $i$ stands for either $x$ or $y$, denoting the direction in cartesian coordinates. With this limitation, friction no longer changes the direction of the flow (Hou et al. 2013a).

\section{Computational examples}

All simulations were carried out with the Hydroinformatics Modeling System (hms). The proposed roughness approach is compared with different roughness models. Results of high-resolution simulations with explicitly discretized microtopography (HR) are used as reference solutions. All models use the same numerical scheme. The parameters of all models are optimized with the SciPy library van der Walt et al. (2011) by minimizing the root mean square deviation (RMSD) of the model results in regard to the HR model, using either Brent's method (Brent 1973) for one free parameter or the Limited-memory Broyden, Fletcher, Goldfarb and Shanno algorithm (L-BFGS-B) (Byrd et al. 1995; Zhu et al. 1997) for more parameters.

The RMSD is calculated as:

$\mathrm{RMSD}=\sqrt{\frac{\sum_{t=1}^{n}\left(\hat{q}_{t}-q_{t}\right)^{2}}{n}}$

Here, $\hat{q}_{t}$ is the unit discharge obtained by the roughness model, $q_{t}$ stands for the unit discharge of the reference solution of a HR model; $t$ is a sample index and $n$ is the number of samples. The normalized root mean square deviation NRMSD is calculated as

$\mathrm{NRMSD}=\frac{\mathrm{RMSD}}{q_{\max }-q_{\min }}$,

where $q_{\max }$ and $q_{\min }$ are the maximum and minimum values of the reference solution calculated by the HR model, respectively.

The computational benefit gained by the coarse grids is quantified with the speedup, which is calculated as

SPEEDUP $=\frac{T}{\hat{T}}$,

whereby $T$ is the walltime duration of the HR model and $\hat{T}$ is the walltime duration of the upscaled model.

\section{Rainfall-runoff over an inclined plane with sine- wave shaped microtopography}

One-dimensional rainfall-runoff over an inclined plane with sine-wave shaped microtopography is simulated. Although synthetic, this test case is suitable to study the capability of roughness models because in the limit, any theory for complex microtopography has to converge to the 
solution of this idealized set up (Thompson et al. 2010). The domain is $4 \mathrm{~m}$ long and its topography is described by

$z_{b}=-0.05 x+0.01 \sin \left(20 \pi x+\frac{\pi}{2}\right)$

for a high-resolution model with explicitly discretized microtopography (HR) on a $0.01 \mathrm{~m}$ grid. The standard deviation of the microtopography is $\sigma=0.01 \mathrm{~m}$. If the microtopography is not explicitly discretized, which is the case in the upscaled models, the bottom elevation is described by

$z_{b}=-0.05 x$.

The side-view of the domain with microtopography (HR) and without (other) is plotted in Fig. 2. Simulation parameters, initial and boundary conditions for this simulation are summarized in Table 1.

Results for the proposed roughness model (RM), Lawrence's model (LAW), constant Manning's coefficient model (CM), variable Manning's coefficient model (VM)

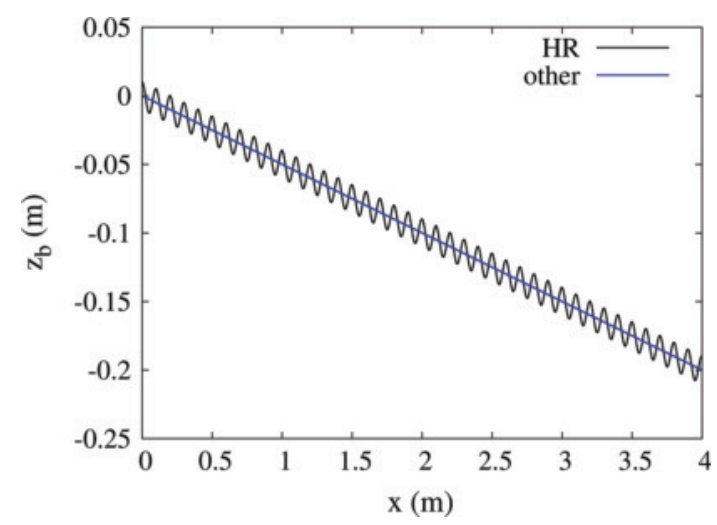

Fig. 2 Rainfall-runoff over an inclined plane with sine-wave shaped microtopography: computational domain of different models: HR (black), all other models (blue)

Table 1 Rainfall-runoff over an inclined plane with sine-wave shaped microtopography: simulation parameters, initial and boundary conditions

\begin{tabular}{lll}
\hline Parameter & Meaning & Value \\
\hline$\sigma$ & Standard deviation & $0.01 \mathrm{~m}$ \\
$I$ & Slope & 0.05 \\
$n$ & Manning's coefficient in reference & $0.04 \mathrm{sm}^{-1 / 3}$ \\
& $\quad$ simulation (HR) & \\
$i$ & Rainfall intensity & $8 \times 10^{-4} \mathrm{~m} / \mathrm{s}$ \\
$T$ & Simulation time & $22.5 \mathrm{~s}$ \\
$\mathrm{BC}_{0}$ & Boundary condition at $x=0$ & Closed boundary \\
$\mathrm{BC}_{4}$ & Boundary condition at $x=4 \mathrm{~m}$ & Open boundary \\
$h_{0}$ & Initial water depth inside the domain & 0 \\
\hline
\end{tabular}

and Razafison's furrow roughness model (RA) using a grid size of $0.1 \mathrm{~m}$ are calculated.

Optimization was carried out regarding the discharge at the outlet of the domain. The optimized parameters for each model together with the resulting RMSDs are given in Table 2. The optimal parameters of the RA model for this test case were taken from the literature (Razafison et al. 2012).

The unit discharges at the outlet of the domain divided by the total unit discharge of the rain $q_{\text {rain }}=3.2$. $10^{-3} \mathrm{~m}^{2} / \mathrm{s}$ are plotted in Fig. 3. The CM model poorly reproduces the HR model result by overshooting it in the early stage of the simulation and undershooting it in the later stage. The VM model with three free parameters shows very good agreement. The RM model shows the best agreement. At the beginning, the RM model slightly overshoots the solution of the HR model, however in the later stages the curves show very good agreement. The LAW model with two calibration parameters shows good agreement with the HR model. The discharge in the early stages of the simulation is overshot by the LAW model, however the later stages are captured well. The discharge calculated by the RA model rises later than all other models and keeps undershooting the HR model results. A discontinuity occurs at about $t=20 \mathrm{~s}$, which marks the time for $\left\langle h_{F}\right\rangle<h$. At the end of the simulation, the RA model catches up with the HR model.

All models can be calibrated to match the HR results to some extent. However, it could be argued that the VM model parameter $h_{0}$ and the LAW model parameter $k$ are geometric parameters and should not be used for calibration. From their conceptual point of view, $h_{0}$ and $k$ should either be set to the standard deviation of microtopography, i.e. $0.01 \mathrm{~m}$, or the amplitude of the microtopography, i.e. $0.02 \mathrm{~m}$. It was found out that using these values for $h_{0}$ and $k$ significantly reduces these models accuracy. Especially the LAW model can not be calibrated to satisfactory accuracy using only $\phi$, because $\phi$ represents a fraction and therefore is bounded between 0 and 1 and is not very sensitive. The

Table 2 Rainfall-runoff over an inclined plane with sine-wave shaped microtopography: calibrated parameter values and corresponding RMSD for each model

\begin{tabular}{lll}
\hline Model & Calibrated parameter(s) & RMSD \\
\hline CM & $n=0.22 \mathrm{sm}^{-1 / 3}$ & 0.081 \\
VM & $n_{0}=0.018 \mathrm{sm}^{-1 / 3}, h_{0}=0.04 \mathrm{~m}, \epsilon=2.4$ & 0.014 \\
LAW & $\phi=5.6 \%, k=0.06 \mathrm{~m}$ & 0.040 \\
RA & $C=0.4, K_{0}, R=0.02$ & 0.058 \\
RM & $n=0.15 \mathrm{sm}^{-1 / 3}, \alpha_{0}=28.57, \alpha_{1}=7.26$ & 0.007 \\
\hline
\end{tabular}

$C M$ constant manning, $V M$ variable manning, $L A W$ Lawrence, $R A$ Razafison, $R M$ proposed approach) 


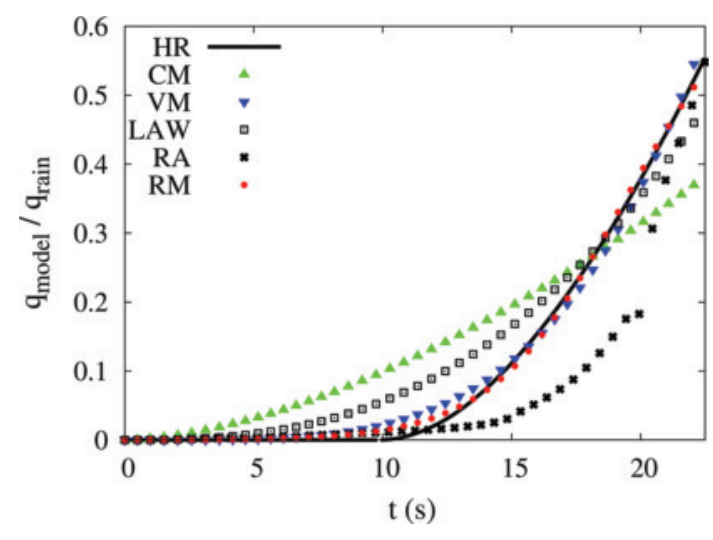

Fig. 3 Rainfall-runoff over an inclined plane with sine-wave shaped microtopography: unit discharges compared at the outlet (HR highresolution, $C M$ constant manning, $V M$ variable manning, $L A W$ Lawrence, $R A$ Razafison, $R M$ proposed approach

simulation of the coarse models runs on a mesh with 40 cells in average 50 times faster than the HR model simulation, which runs on a mesh with 400 cells.

\section{Flow over an inclined plane with random microtopography}

Study area

The following example simulates a run-dry process of an inclined surface with random microtopography. The study area is a $4 \mathrm{~m} \times 1 \mathrm{~m}$ inclined plane (cf. Fig. 4 (top)). Random microtopography is generated as square blocks with a horizontal length of $0.05 \mathrm{~m}$ and a vertical elevation according to a Gaußian distribution with a standard deviation of $\sigma=0.02 \mathrm{~m}$ (cf. Fig. 4 (bottom)). The maximum value of the microtopography is about $0.07 \mathrm{~m}$ and the minimum value about $-0.08 \mathrm{~m}$. The domain is initially ponded with water which is then discharged during the simulation at the outlet of the domain. Several simulations with different slope and initial water depth are carried out.

The slope $I$ and the initial water depth $h_{0}$ are varied for different simulation runs. For each different slope and each different water depth, different simulation runs. The slope is increased in steps of 0.01 and the water depth is increased in steps of $0.005 \mathrm{~m}$. For example, for $I=-0.01$, simulation runs with $h_{0}=0.005 \mathrm{~m}, h_{0}=0.01 \mathrm{~m}, h_{0}=0.015 \mathrm{~m}$ until $h_{0}=0.08 \mathrm{~m}$ are carried out, and after that the slope is set to $I=-0.02$ and again simulation runs with varying $h_{0}$ are carried out. Table 3 shows the simulation parameters, initial and boundary conditions for this simulation.

Four different roughness models are compared for every possible combination of $I$ and $h_{0}$ with results of a highresolution model explicitly discretizing the microtopography (HR): a model using a calibrated constant Manning's
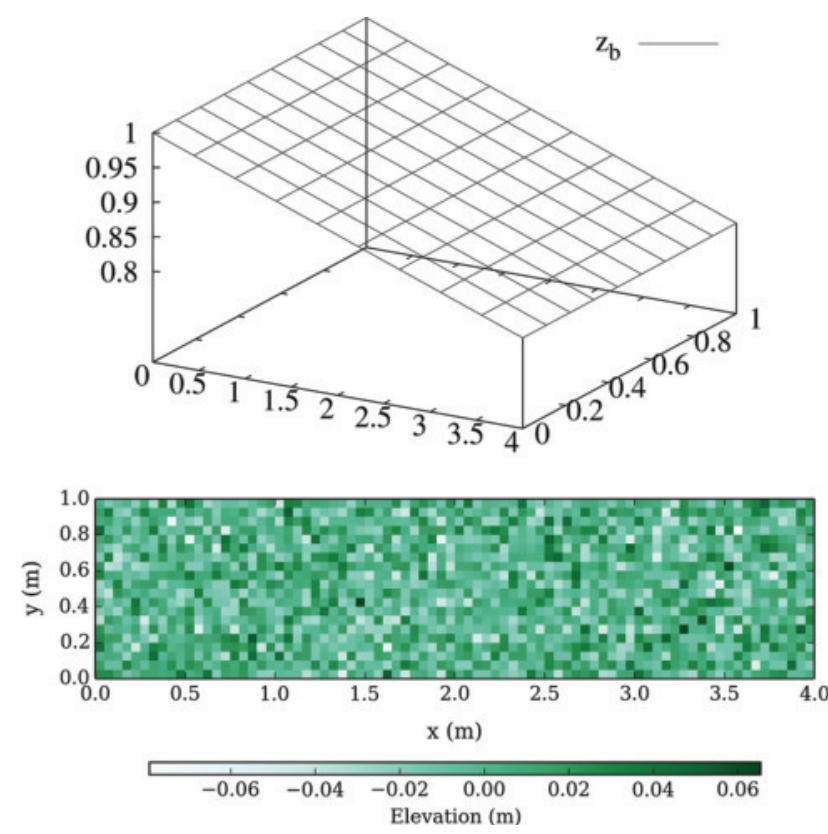

Fig. 4 Flow over an inclined plane with random microtopography: global topography for $I=0.05$ (top); microtopography (bottom)

coefficient (CM); a model using a variable Manning's coefficient (VM), Lawrence's model (LAW); and the proposed roughness approach (RM). The HR model uses quadratic grid cells with an edge length of $0.01 \mathrm{~m}$, all other models use grids with coarser cells.

\section{Uncalibrated model on coarse grid}

First, an uncalibrated simulation on a coarse grid is carried out to show the effects of increasing the grid size without using an upscaling approach. The simulation is run on a $0.05 \mathrm{~m} \times 0.05 \mathrm{~m}$ grid using the same roughness coefficient as the HR model $\left(n=0.02 \mathrm{sm}^{-1 / 3}\right)$ for $I=-0.02$, $h_{0}=0.04 \mathrm{~m}$. Results for the unit discharge at the outlet for the uncalibrated model (UCM) are plotted in Fig. 5 (top). The peak of the discharge curve of the UCM model is about 20 times higher than the HR model. After the peak is reached, the UCM model discharge decreases too quickly which indicates that the roughness is overall underestimated. A NRMSD of 1.0 is calculated.

\section{Application to different hydraulic conditions}

In this section, the applicability of the roughness models to different hydraulic conditions is tested. In a first step, the models are calibrated for a fixed $I-\Lambda_{0}$ combination and in a second step these calibrated models are applied to different $I-\Lambda_{0}$ combination.

All models were calibrated on a $0.05 \mathrm{~m} \times 0.05 \mathrm{~m}$-grid with regard to the unit discharge calculated by the HR 
Table 3 Flow over an inclined plane with random microtopography: simulation parameters, initial and boundary conditions

\begin{tabular}{lll}
\hline Parameter & Meaning & Value \\
\hline$\sigma$ & Standard deviation & $0.02 \mathrm{~m}$ \\
$I$ & Slope & $0.01,0.02, \ldots, 0.14$ \\
$n$ & Manning's coefficient in reference simulation (HR) & $0.04 \mathrm{sm}^{-1 / 3}$ \\
$i$ & Rainfall intensity & 0 \\
$T$ & Simulation time & $60 \mathrm{~s}$ \\
$\mathrm{BC}_{0}$ & Boundary condition at $x=0$ & Closed boundary \\
$\mathrm{BC}_{4}$ & Boundary condition at $x=4 \mathrm{~m}$ & Open boundary \\
$\mathrm{BC}_{\|}$ & Boundary conditions at $y=0$ and $y=1$ & Closed boundary \\
$h_{0}$ & Initial water depth inside the domain & $0.005,0.01,0.015, \ldots, 0.08 \mathrm{~m}$ \\
\hline
\end{tabular}

Table 4 Flow over an inclined plane with random microtopography, $0.05 \mathrm{~m}$ grid size: calibrated parameter values and corresponding NRMSD for $h_{0}=0.04 \mathrm{~m}$ and $I=0.02$ for each model

\begin{tabular}{lll}
\hline Model & Calibrated parameter(s) & NRMSD \\
\hline CM & $n=0.18 \mathrm{sm}^{-1 / 3}$ & 0.120 \\
VM & $n_{0}=0.14 \mathrm{sm}^{-1 / 3}, h_{0}=0.045 \mathrm{~m}, \epsilon=1.4$ & 0.026 \\
LAW & $\phi=50 \%, k=0.023 \mathrm{~m}$ & 0.173 \\
RM & $n=0.112 \mathrm{sm}^{-1 / 3}, \alpha_{0}=5.52, \alpha_{1}=2.61$ & 0.030 \\
\hline
\end{tabular}

$C M$ constant manning, $V M$ variable manning, $L A W$ Lawrence, $R M$ proposed approach

model at the outlet of the domain for a slope of $I=-0.02$ and an initial water depth of $h_{0}=0.04 \mathrm{~m}$, i.e. an initial inundation ratio of $\Lambda_{0}=h_{0} / \sigma=2$. The calibrated parameters of all models with the corresponding NRMSDs are given in Table 4 . The unit discharges at the outlet are plotted in Fig. 5 (bottom). While the LAW model is showing the worst agreement with the HR model, the VM model agrees the best, followed by the RM model. Although the first peak of the HR model can not be captured by any of the models, overall the VM and RM models capture the HR model results very well. The CM model undershoots the HR solution significantly at the beginning of the simulation and starts to overshoot it after about $t=12 \mathrm{~s}$. The overall agreement is not satisfactory. Additional calibrations which were carried out with different initial conditions suggest that all models except the LAW model should be calibrated for $\Lambda_{0} \geq 2$, because for $\Lambda_{0}<2$ the calibration may fail to deliver good results. One reason for this may be, that for $\Lambda_{0}<2$ the blockade effects of the microtopgraphy outweigh its roughness effects, i.e. the flow depends on the spatial configuration and geometric properties of single microtopography elements. Then, spatial heterogeneity significantly influences the flow and therefore the roughness effects can not be averaged over the domain. For $h_{0}=0.04 \mathrm{~m}$, the LAW model uses Eq. 11 to calculate the roughness and therefore has no calibration parameters. The
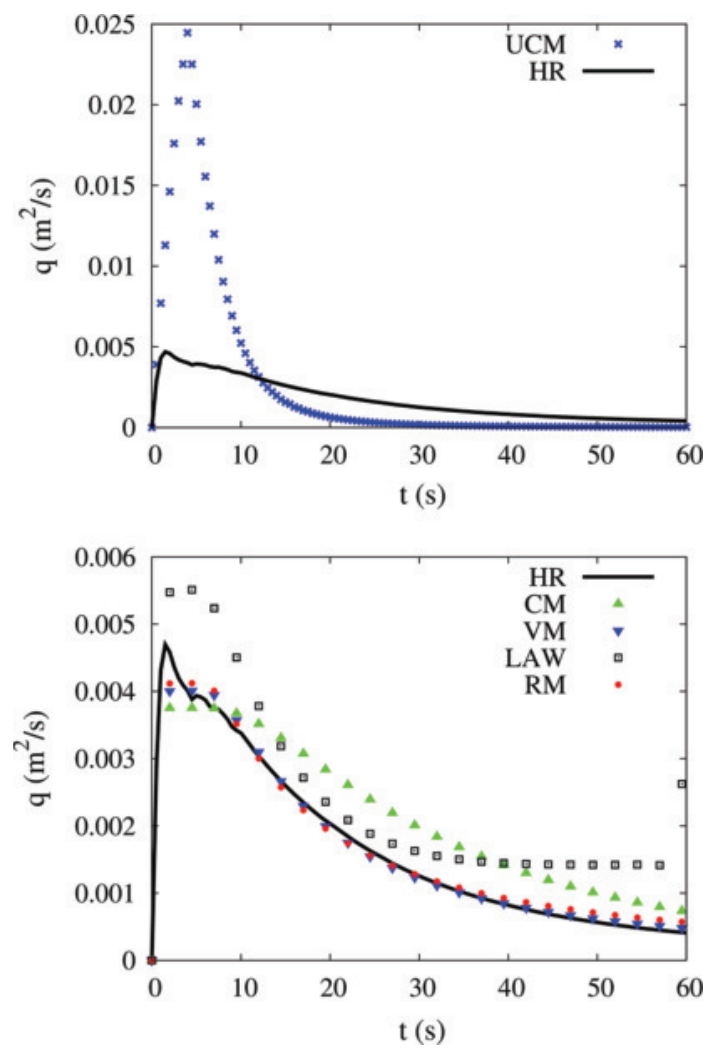

Fig. 5 Flow over an inclined plane with random microtopography, $0.05 \mathrm{~m}$ grid size: unit discharges of the uncalibrated model (UCM) and HR models (top) and model comparison at the outlet for $h_{0}=$ $0.04 \mathrm{~m}$ and $I=0.02$ (bottom) (HR high-resolution, $C M$ constant manning, $V M$ variable manning, $L A W$ Lawrence, $R M$ proposed approach)

calibrated values in Table 4 effect only the stage of the simulation when the inundation ratio becomes smaller than 1. Calibrating the LAW model for smaller $\Lambda_{0}$ might deliver better results, however the calibration difficulties regarding the LAW model mentioned in the test case before still remain.

To study the transferability of the calibrated parameters to different hydraulic conditions, the calibrated parameters 
in Table 4 are used to simulate the unit discharge for every $I-\Lambda_{0}$ combination. The grid cell size used by the models is $0.05 \mathrm{~m}$. Results are compared with HR model results. Figure 6 shows the NRMSD of all models in dependency of $I$ and $\Lambda_{0}$, where each cell is the result of a simulation run of a certain $I-\Lambda_{0}$ combination. The main focus of Fig. 6 is the change of the NRMSD in dependency of $I$ and $\Lambda_{0}$ within one model. Because of this reason and the significant differences in the NRMSDs of different models, the range of the legends are not set equal. The $I-\Lambda_{0}$ combination used for the calibration is denoted with a black rectangle. High NRMSD in the CM model results occur for small $\Lambda_{0}$ combined with small $I$. As $\Lambda_{0}$ or $I$ increase, the NRMSD decreases as the influence of the microtopography decreases. The minimum NRMSD occurs for the calibration conditions, i.e. $\Lambda_{0}=2$ and $I=-0.02$. Except for the region around $\Lambda_{0}=0.75$ and $I=-0.01$, which is the location of the maximum NRMSD, the transfer of the calibrated parameters to different $I$ and $\Lambda_{0}$ does not signifi-

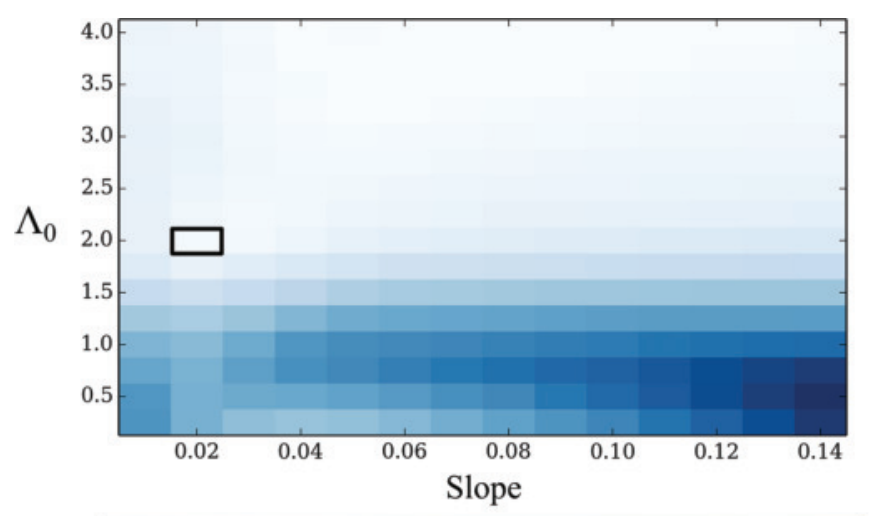

\begin{tabular}{lll}
\hline 1 & 1 & 1 \\
\hline 0.04 & RM & 0.28
\end{tabular}

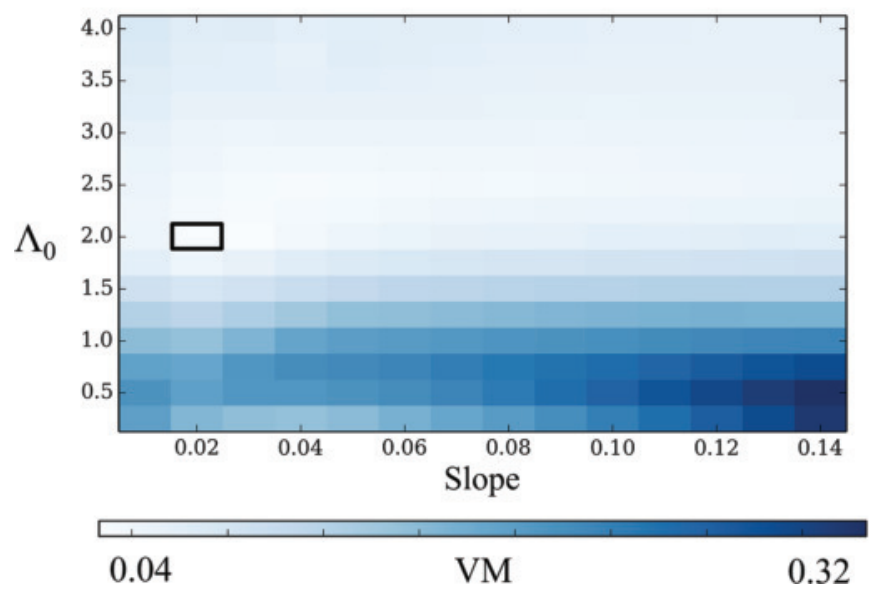

cantly alter the NRMSD. It stays almost constant around the mean value of 0.133 . The NRMSD distributions of the VM model and the RM model are qualitatively very similar. High NRMSD occurs for small $\Lambda_{0}$ combined with large $I$. For the VM model, the minimum NRMSD occurs for the calibration conditions, but for the RM model smaller NRMSD is calculated for other simulation runs. For both models, transfering the calibrated parameters to hydraulic conditions with $\Lambda_{0}>1.5$ leads to increased NRMSDs, but transfering the parameters to conditions with higher $\Lambda_{0}$ has not a significant influence on the NRMSD. The LAW model has the highest NRMSD of all considered models. The NRMSD increases significantly for $\Lambda_{0}<1$, for $\Lambda_{0}>1$ the NRMSD is about 0.15 and remains constant. With increasing $\Lambda_{0}$, the NRMSD decreases. The maximum NRMSD, the minimum NRMSD and the mean NRMSD of all simulations for each model are given in Table 5. Here it is seen that the RM model calculates a smaller minimum, maximum, and mean NRMSD than the VM model, but the

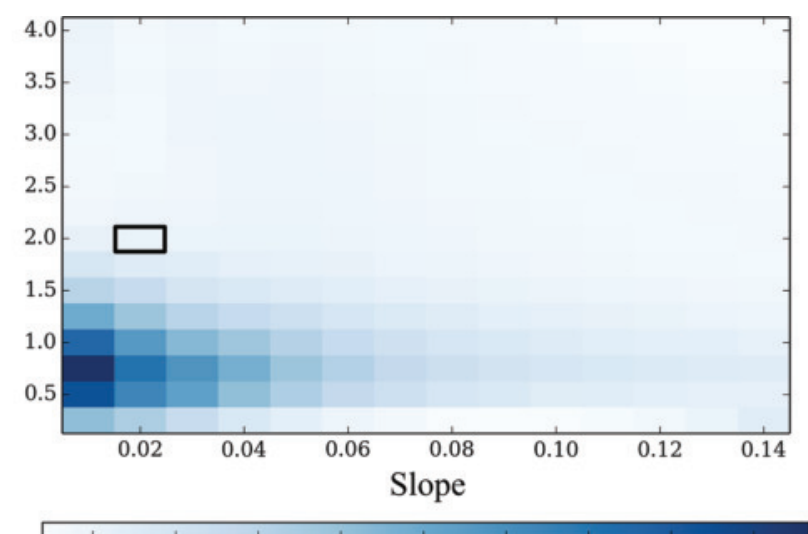

$\begin{array}{lll}0.12 & \mathrm{CM} & 0.44\end{array}$

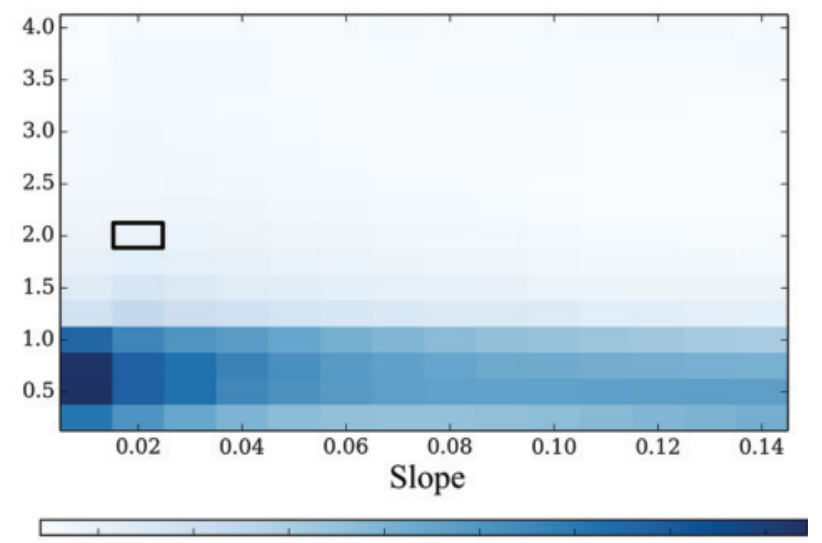

0.2

Fig. 6 Flow over an inclined plane with random microtopography, $0.05 \mathrm{~m}$ grid size: normalized root mean square deviation in relation to initial inundation ratio $\Lambda_{0}$ and slope $I$ 
Table 5 Flow over an inclined plane with random microtopography, $0.05 \mathrm{~m}$ grid size: Minimum (min), maximum (max) and mean NRMSD values of all $I-\Lambda_{0}$-combinations for different models

\begin{tabular}{llll}
\hline Model & Min & Max & Mean \\
\hline CM & 0.095 & 0.468 & 0.133 \\
VM & 0.026 & 0.347 & 0.105 \\
LAW & 0.093 & 1.688 & 0.335 \\
RM & 0.022 & 0.304 & 0.091 \\
\hline
\end{tabular}

$C M$ constant manning, $V M$ variable manning, $L A W$ Lawrence, $R M$ proposed approach

VM model can be locally calibrated to show better agreement (cf. Fig. 5 (bottom)).

\section{Application to different cell size}

Grid size is increased from 0.05 to $0.1 \mathrm{~m}$ and to $0.2 \mathrm{~m}$ to study the transferability of the calibrated parameters to different meshes. It is desirable, that the RMSD decreases with decreasing cell size (also called grid convergence) because this allows to efficiently calibrate the model on coarser cells and then transfer the calibrated parameters to a model with the desired spatial resolution (Horritt and Bates 2001). If this can not be achieved, it is desirable that at least the RMSD stays the same for different cell sizes. Table 6 shows the NRMSD in dependency of grid cell length averaged over all $I-\Lambda_{0}$-combinations. For all models, the calibrated parameters were transferred between the investigated scales with negligibly small change in the NRMSD. Oddly, coarsening the grid size to $0.2 \mathrm{~m}$ improves the NRMSD. The reason for this negligibly small improvement may be due to numerical round-off somehow benefiting the accuracy of the solution, yet this has not been further investigated. The inclined plane as a study area is not very sensitive to grid size, because the geometry is captured perfectly accurate by the second order discretization in combination with the non-negative hydrostatic reconstruction (cf. Simons et al. 2014). The plane has no other spatial heterogeneities than the subgrid-scale microtopography, which is accounted for by the roughness formulation, i.e. the model domain is a smooth inclined plane. Therefore, increasing grid size is not associated with further loss of geometric information and only reduces accuracy because of numerical diffusion. The HR model simulation runs on a mesh with 40,000 cells. The speedup (Eq. 24) in relation to the cell number is shown in Table 7. As the cell number decreases, the speedup increases. The speedup of the different upscaled roughness models did not differ significantly (Table 7).
Table 6 Flow over an inclined plane with random microtopography: mean NRMSD in dependency of grid cell length averaged over all $I-\Lambda_{0^{-}}$ combinations

Table 7 Flow over an inclined plane with random microtopography: computational benefit for different grid sizes $\Delta x$

\begin{tabular}{llrr}
\hline Model & $\Delta x(\mathrm{~m})$ & Cell number & SPEEDUP \\
\hline HR & 0.01 & 40,000 & 1 \\
Other & 0.05 & 1600 & 20 \\
Other & 0.1 & 400 & 40 \\
Other & 0.2 & 100 & 70 \\
\hline
\end{tabular}

$H R$ high-resolution, other: all upscaled roughness models

\section{Rainfall-runoff in a small alpine catchment}

\section{Study area and preliminary studies}

Hortonian overland flow in a natural catchment, the Heumöser slope, Vorarlberg Alps, Austria, is simulated. The study area is a $100,000 \mathrm{~m}^{2}$ large subcatchment of the Heumöser slope. Bottom elevation of the area is provided in $1 \mathrm{~m} \times 1 \mathrm{~m}$ resolution by a digital elevation model of the Austrian department Torrent and Avalanche Control. This bottom elevation is used for the high-resolution model. Figure 7 (top) shows the topography of the domain and the location of the outlet, where discharge was measured. Rainfall is imposed according to a time series measured in July 2008 with a resolution of 10 min (Fig. 7 (middle)). The simulation runs for $t=120 \mathrm{~h}$, i.e. 5 days.

Extensive numerical simulations of surface and subsurface runoff for this domain were carried out in Simons et al. (2014), Stadler et al. (2012) within Research Unit 'Coupling of flow and deformation processes for modelling the movement of natural slopes' funded by the German Research Foundation (Hinkelmann et al. 2011). During these simulations, the model was calibrated with a runoff coefficient $\Psi=0.3$ in combination with a linear reservoir model to account for the slower discharge component in the subsurface, which was identified as a crucial contributor to the discharge at the outlet of the domain. The linear reservoir is described by the following equations: 

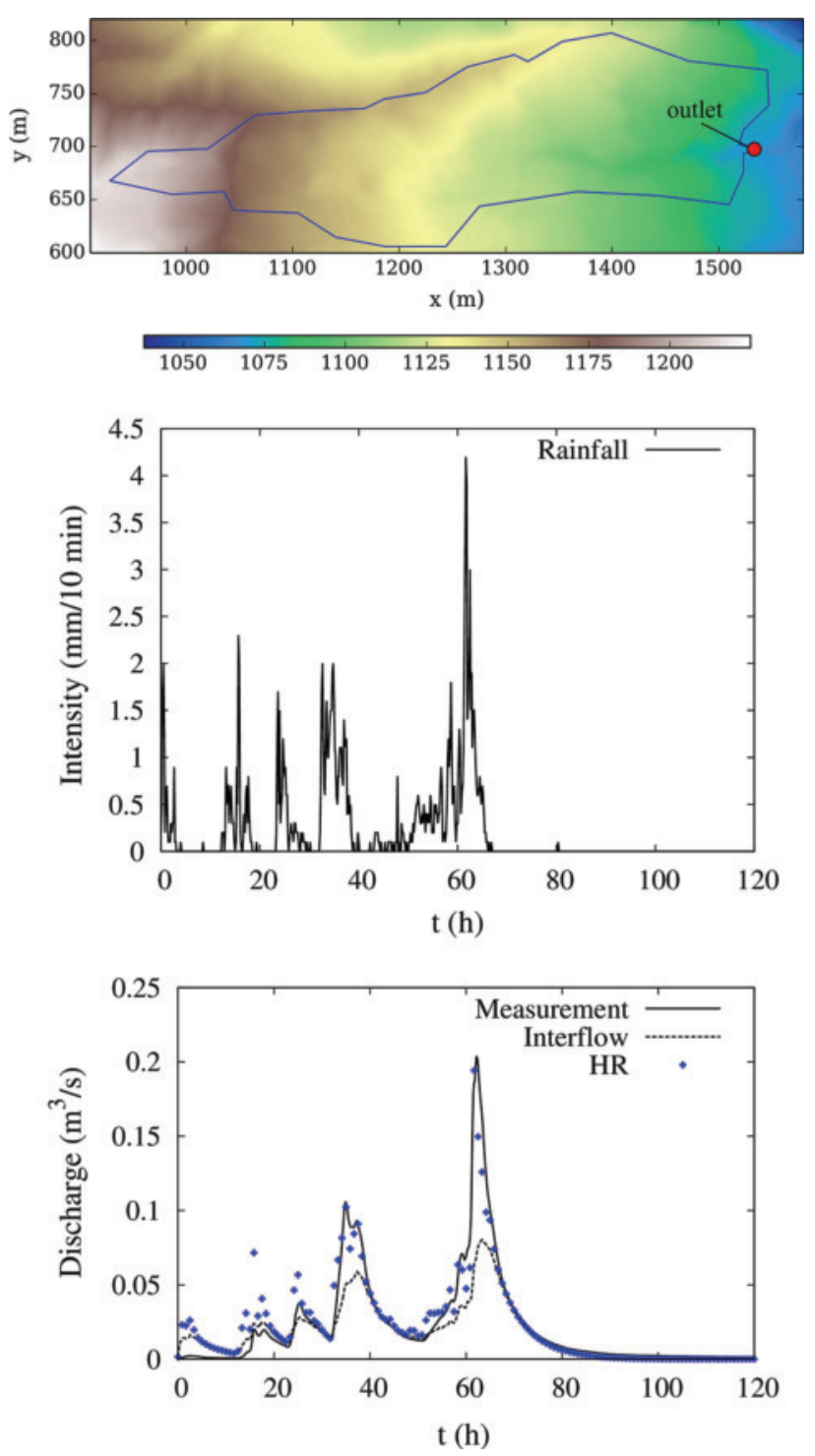

Fig. 7 Rainfall-runoff in a small alpine catchment: bottom elevation, watershed (blue) and location of the outlet (top); intensity of the rainfall event plotted over time (middle); HR model results with parameters from Simons et al. (2014) (bottom)

$\frac{\mathrm{d} S(t)}{\mathrm{d} t}=I(t)-Q(t)$

$S(t)=K Q(t)$

Here, $S(t)$ stands for the storage at time $t ; I(t)$ for the inflow; and $Q(t)$ for the outflow of the reservoir. $K$ is the constant of proportionality which can be obtained by calibration. A calibration in Simons et al. (2014) resulted in a constant of proportionality $K=6 \mathrm{~h}$ and a Manning coefficient of $n=0.067 \mathrm{sm}^{-1 / 3}$. Because the same numerical model (hms) as in Simons et al. (2014) is used in this
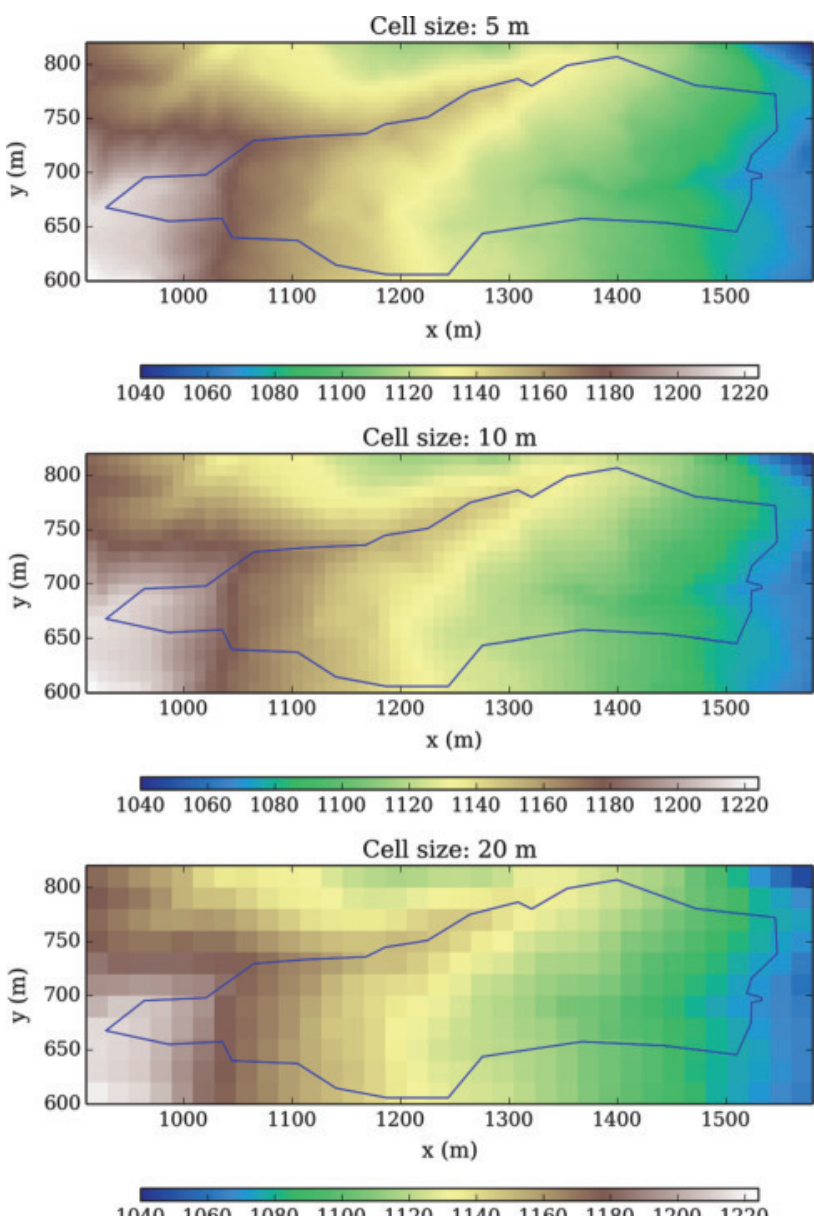

Fig. 8 Rainfall-runoff in a small alpine catchment: bottom elevation discretization in dependency of mesh resolution

study, the same values for $\Psi$ and $K$ are used in all models. For reference, the results of a high-resolution simulation with these parameters on a $1 \mathrm{~m} \times 1 \mathrm{~m}$ grid (HR) is plotted in Fig. 7 (bottom).

In the simulations grids with cell sizes of 5, 10 and $20 \mathrm{~m}$ are used. The bottom elevation inside a cell is set to the arithmetic average of all DEM points located inside the cell. The discretized bottom elevation for the studied cases is given in Fig. 8. As expected, the discretization with a cell size of $5 \mathrm{~m}$ (Fig. 8 (top)) has the most information about local details in the topography. It also can be seen that the discretization with a cell size of $10 \mathrm{~m}$ (Fig. 8 (middle)) still represents an acceptable amount of local heterogeneities and even the discretization with a cell size of $20 \mathrm{~m}$ (Fig. 8 (bottom)) is able to capture the main topologic characteristics of the catchment. However, in the latter case the watershed boundaries start to blur and the location of the measurement weir is captured in a single cell. Small scale 
preferential flow paths in the domain as observed in Simons et al. (2014) can not be represented by the coarse resolution. Additionally, numerical diffusion increases due to the mesh resolution effects ( $\mathrm{Yu}$ and Lane 2006). All these effects have to be captured to some extent by the roughness formulations.

In order to calculate its standard deviation, the microtopography is isolated by calculating the deviations of each DEM point in a cell from the bottom elevation of the cell. The standard deviation of the microtopography is then calculated as $\sigma=0.19 \mathrm{~m}$ for a grid cell size of $5 \mathrm{~m}$ and $\sigma=0.21 \mathrm{~m}$ for a grid cell size of 10 and $20 \mathrm{~m}$.

Table 8 shows the simulation parameters, initial and boundary conditions for this simulation.

The proposed roughness formulation (RM) and three other roughness approaches are compared in this test case: calibrated constant Manning's coefficient (CM), variable Manning's coefficient (VM) and the model of Lawrence (LAW). Model discharges at the outlet are superposed with the interflow computed by the linear reservoir (cf. Eqs. 27 and 28) and are compared with measurement data.

Table 8 Rainfall-runoff in a small alpine catchment: simulation parameters, initial and boundary conditions

\begin{tabular}{|c|c|c|}
\hline Parameter & Meaning & Value \\
\hline$\sigma$ & Standard deviation & $\begin{array}{l}0.19 \mathrm{~m}(\Delta x=5 \mathrm{~m}), 0.21 \mathrm{~m} \\
\quad(\Delta x=10,20 \mathrm{~m})\end{array}$ \\
\hline$I$ & Slope & Locally varying \\
\hline$n$ & $\begin{array}{l}\text { Manning's coefficient in } \\
\text { reference simulation (HR) }\end{array}$ & $0.067 \mathrm{sm}^{-1 / 3}$ \\
\hline$i$ & Rainfall intensity & According to a time series \\
\hline$T$ & Simulation time & $120 \mathrm{~h}$ \\
\hline $\mathrm{BC}$ & Boundary condition & Open boundary \\
\hline$h_{0}$ & $\begin{array}{l}\text { Initial water depth } \\
\text { inside the domain }\end{array}$ & 0 \\
\hline
\end{tabular}

Table 9 Rainfall-runoff in a small alpine catchment, $10 \mathrm{~m}$ grid size: calibrated parameter values and corresponding RMSD for each model

\begin{tabular}{lll}
\hline Model & Calibrated parameter(s) & RMSD \\
\hline HR & $n=0.067 \mathrm{sm}^{-1 / 3}$ & 0.011 \\
CM & $n=0.115 \mathrm{sm}^{-1 / 3}$ & 0.010 \\
VM & $n_{0}=0.01 \mathrm{sm}^{-1 / 3}, h_{0}=0.058 \mathrm{~m}, \epsilon=0.11$ & 0.012 \\
LAW & $\phi=10 \%, k=0.21 \mathrm{~m}$ & 0.012 \\
RM & $n=0.035 \mathrm{sm}^{-1 / 3}, \alpha_{0}=0.3, \alpha_{1}=0.87$ & 0.010 \\
\hline
\end{tabular}

$H R$ high-resolution, $C M$ constant manning, $V M$ variable manning, $L A W$ Lawrence, $R M$ proposed approach

\section{Upscaling with roughness formulations}

Models are calibrated for a quadratic grid with a cell size of $10 \mathrm{~m}$. Table 9 shows the calibrated model parameters and the corresponding RMSD with regard to measurement data for each model. All models have almost the same RMSD, however the RM model and the CM model give the lowest RMSD. The HR model results in a similar RMSD as the coarse models. The reason is that due to computational restraints, the HR model was calibrated manually with fewer trials than an optimization algorithm would require (Simons et al. 2014). The usage of numerical optimization algorithms to calibrate the HR model would demand unfeasibly high computational effort. The hydrograph calculated by the HR model is compared with measurement data in Fig. 7 (bottom). In the early stages of the rainfall event, specifically for $t<20 \mathrm{~h}$, the interflow is overestimated by the linear reservoir model and thus, the HR model results overshoot the measured data significantly. Reason for this deviation might be previous hydrological events in the catchment, which can not be taken into account. This can be seen in Fig. 7 (bottom), where at the beginning of the simulation the interflow overshoots the measured time series. Most likely, in the real event the rainfall infiltrated into the groundwater instead of becoming part of the interflow. Better results might be obtained by using a more sophisticated approach than a constant runoff coefficient to estimate the effective rainfall. At around $t=20 \mathrm{~h}$ the deviation between model and measurement begins to decrease. After $t=30 \mathrm{~h}$, the hydrograph is captured quite accurately by the models. The hydrographs of the CM, VM, LAW and RM model are plotted in Fig. 9 (blue triangles). As the HR model, these models also overshoot the measurement data for $t<20 \mathrm{~h}$. The CM model shows good agreement for the calibrated cell size. Both peaks are captured well. The VM model captures both occuring peaks (at about $t=35 \mathrm{~h}$ and $t=65 \mathrm{~h}$ ) the best. The LAW model and the RM model tend to undershoot both peaks. However, the RM model captures the tails of both curves more accurately.

\section{Application to different cell size}

In order to investigate the transferability of calibrated parameters to different resolutions, cell size is varied to 5 and $20 \mathrm{~m}$. Table 10 shows the RMSD for each model in dependency of cell size. In Fig. 9, the hydrographs for a cell edge length of $5 \mathrm{~m}$ (red circle) and a cell edge length of $20 \mathrm{~m}$ (black square) are plotted. For the CM model, varying the cell size decreases both peaks and decreases the arrival time of the first wave. In Table 10 it can be seen that the 

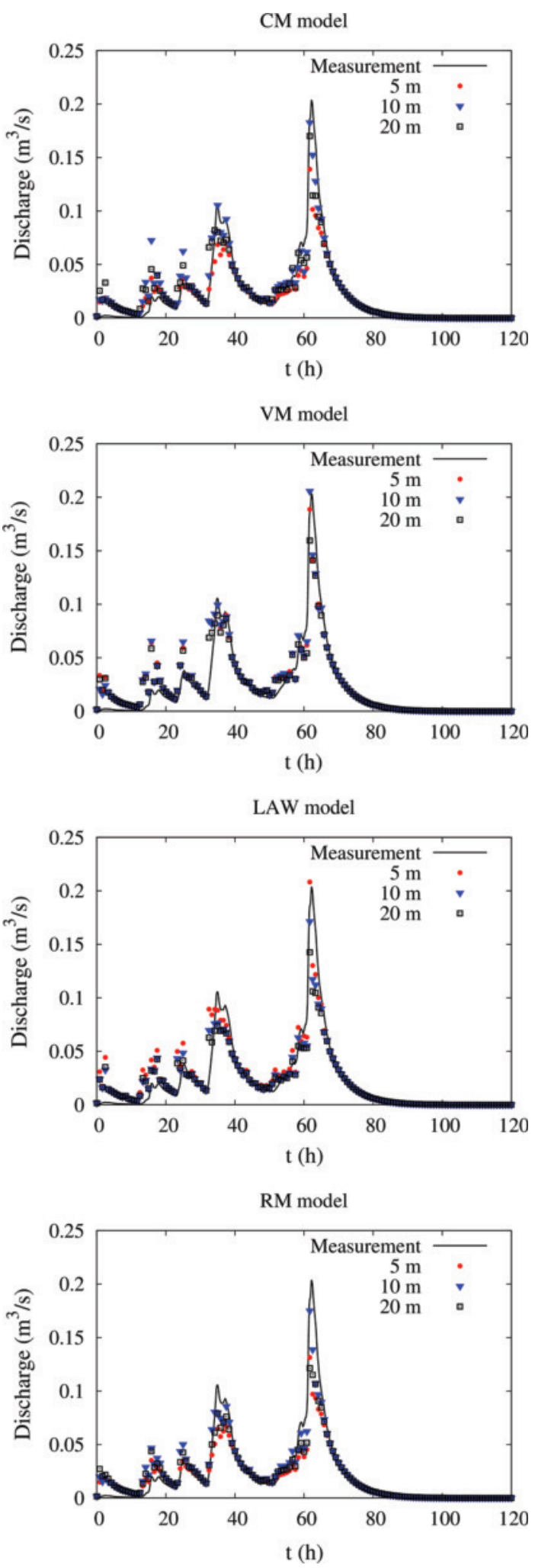

Fig. 9 Rainfall-runoff in a small alpine catchment: discharges of different models
Table 10 Rainfall-runoff in a small alpine catchment: RMSD for each model in dependency of cell size

\begin{tabular}{llll}
\hline Model & $5 \mathrm{~m}$ & $10 \mathrm{~m}$ & $20 \mathrm{~m}$ \\
\hline $\mathrm{CM}$ & 0.015 & 0.010 & 0.013 \\
$\mathrm{VM}$ & 0.012 & 0.012 & 0.012 \\
LAW & 0.013 & 0.012 & 0.014 \\
$\mathrm{RM}$ & 0.016 & 0.010 & 0.013 \\
\hline$C M$ & constant & \multicolumn{4}{l}{ manning, $\quad V M$} \\
variable manning, $L A W$ & Lawr- \\
ence, $R M$ proposed approach
\end{tabular}

Table 11 Rainfall-runoff in a small alpine catchment: Computational benefit for different grid sizes $\Delta x$

\begin{tabular}{lccc}
\hline Model & $\Delta x(\mathrm{~m})$ & Cell number & SPEEDUP \\
\hline HR & 1 & 147,400 & 1 \\
Other & 5 & 5896 & 56 \\
Other & 10 & 1474 & 336 \\
Other & 20 & 374 & 2520 \\
\hline
\end{tabular}

$H R$ high-resolution, other all upscaled roughness models

RMSD increases with varying cell size. For the VM model, increasing or decreasing the cell size lowers both peaks (Fig. 9). For the LAW model, mesh refinement leads to an overall increase in discharge and increasing the cell size leads to an overall decrease in the discharge. Varying the cell size for the RM model leads to a significant decrease in both peaks. The arrival time of both waves is captured accurately in all cases. In Table 10 it can be seen that the VM model shows good transferability, while the calibration of the CM, LAW and RM model results show higher RMSDs if the cell size is changed.

A manual calibration of the RM model was carried out to further investigate this models parameters transferability. It was found out that the transferability of the parameters of the RM model can be increased if accuracy is sacrificed. For $n=0.07 \mathrm{sm}^{-1 / 3}, \alpha_{0}=0.51$ and $\alpha_{1}=0.54$, which result in a RMSD $=0.012$, the RM model showed good transferability of its parameters across the investigated cell sizes.

The speedup, as calculated according to Eq. 24, in dependency of grid cell size is shown in Table 11. As expected, increasing the cell size reduces the cell number and thus the computational effort significantly. The speedup of the different roughness models is about the same. Of course the computational time depends on the hardware and the numerical code, however the speedup certainly can be transferred with little variance to different hardware and codes. 


\section{Discussion}

The speedup in the presented examples varied in a wide range between 20 to 2520 (cf. Tables 7, 11). The width of the range can be explained with the way the cell size influences the speedup. In fact, the two major influences on the speedup are the number of cells and the CourantFriedrichs-Lewy stability criterion (CFL), which limits the time step size (Kim et al. 2014). Both the number of cells and the CFL criterion are dependent on the cell size. In Kim et al. (2014), these effects have been taken into account to express a relationship between computational cost $C$ with cell size $\Delta x$ as

$$
C \sim k \Delta x^{-3}
$$

where $k$ is a factor which depends on the computational scheme. The additional operations performed for the calculation of the source terms have been found insignificant, which is the reason why all models get the same speedup for the same cell size, i.e. same number of cells. However, in Table 7 the coarse grid has 400 times less cells than the high-resolution grid causing a speedup of 70 . In contrast, the coarse grid of Table 11 has roughly the same factor of decrease in cell numbers with respect to its high-resolution grid, however the speedup is 2520 . The variation in the speedup might be related to the total duration of the simulation. As the decrease in cell numbers decreases the number of floating point operations per time step, the longer the simulation runs the higher the deviation between the walltime durations of both models becomes.

Another issue to be discussed is the calibration effort. While in general it can be assumed that the calibration effort increases with increasing number of calibration parameters, the calibration effort is very dependent on the initial guess. The authors have shown in Özgen et al. (2015), that due to this dependency, sometimes models with three calibration parameters require less calibration steps than models with two parameters. However, in this work, the calibration of the constant Manning model with one parameter required significantly less calibration steps. This is also related to the optimization methods, because scalar functions can be optimized very efficiently while functions of higher dimension require more sophisticated and computationally demanding optimization methods. In the authors' opinion, the additional accuracy of the variable Manning or the proposed roughness approach outweighs the higher calibration effort. It should also be mentioned, that even if the calibration step is taken into account, the coarse grid simulations are faster than the high-resolution simulation in the investigated cases. Further, as seen in the last example, the high-resolution simulation itself needs to be calibrated for real case applications.

\section{Conclusions}

A novel conceptual roughness formulation for shallow water simulations on coarse grids was developed. The formulation is dependent on the inundation ratio, which is calculated using the standard deviation of the microtopography with regard to its mean value. A physical interpretation of the free parameters was given: the parameter $C_{0}$ is an increased Chézy coefficient, $\alpha_{0}$ is an additional dimensionless roughness coefficient accounting for the microtopography and $\alpha_{1}$ is a geometric conveyance parameter. The presented roughness formulation was then compared to several existing roughness formulations from literature. It was demonstrated in three computational examples, that high-resolution results can be approximated with satisfactory accuracy by calibrating the roughness formulation parameters. The exact values of the calibration parameters may vary in dependency of the numerical methods used to solve the equations, hence the optimized parameters reported in this study should be taken with caution.

The first example studied one-dimensional rainfall-runoff over a sine-wave shaped microtopography. The presented roughness approach returned the lowest root mean square deviation from the high-resolution model results. In the second example, calibrated parameters were transferred to different hydraulic conditions with some success. Varying the slope or the initial inundation increased the error for all models. The presented roughness formulation, together with the variable Manning's coefficient, resulted in the lowest root mean square deviations. It was shown that the proposed roughness formulation can be calibrated more accurately than the variable Manning's coefficient formulation, however, the latter showed a better calibration stability. In the last example, the proposed roughness approach was tested for a real case application. Here, again the presented roughness formulation and the variable Manning's coefficient approach were shown to be good trade-offs between accuracy and computational efficiency. It was shown that it is possible to upscale shallow water models using suitable roughness formulations. Due to mesh resolution effects (Horritt and Bates 2001; Yu and Lane 2006), the coarse grid models are not able to reproduce the high-resolution solutions exactly. In general, it can be concluded that accuracy increases with the number of free calibration parameters. However, as the number of parameters increases, the calibration process becomes more difficult. Using coarser grids resulted in a speedup between 20 and 2520. The reasons for the wide range of the speedup have been discussed. Overall, the proposed roughness approach is superior when compared to the other roughness approaches with respect to accuracy. 
Acknowledgments The authors thank the Alexander von Humboldt-Foundation for the Humboldt Research Fellowship granted to Dr. Dongfang Liang. Parts of the numerical simulations were computed on the supercomputers of Norddeutscher Verbund für Hochund Höchstleistungsrechnen in Berlin. The authors are grateful to Ulrich Razafison from Université de Franche-Comté, France, for the correspondence on his shallow water model.

\section{References}

Audusse E, Bouchut F, Bristeau MO, Klein R, Perthame B (2004) A fast and stable well-balanced scheme with hydrostatic reconstruction for shallow water flows. SIAM J Sci Comput 25(6):2050-2065. doi:10.1137/S1064827503431090

Brent RP (1973) Algorithms for minimization without derivatives. Prentice-Hall, Englewood Cliffs, New Jersey

Byrd RH, Lu P, Nocedal J (1995) A limited memory algorithm for bound constrained optimization. SIAM J Sci Stat Comput 16(5):1190-1208

Defina A (2000) Two-dimensional shallow flow equations for partially dry areas. Water Resour Res 36(11):3251-3264. doi:10.1029/2000WR900167

Delestre O, Cordier S, Darboux F, James F (2012) A limitation of the hydrostatic reconstruction technique for Shallow Water equations. C R Math 350(13-14):677-681. doi:10.1016/j.crma.2012. 08.004

Dottori F, Di Baldassarre G, Todini E (2013) Detailed data is welcome, but with a pinch of salt: accuracy, precision, and uncertainty in flood inundation modeling. Water Resour Res 49(9):6079-6085. doi:10.1002/wrcr.20406

Farmer CL (2002) Upscaling: a review. Int J Numer Method Fluid 40(1-2):63-78. doi:10.1002/fld.267

Fu S, Cao L, Liu B, Wu Z, Savabi M (2015) Effects of DEM grid size on predicting soil loss from small watersheds in China. Environ Earth Sci 73(5):2141-2151. doi:10.1007/s12665-014-3564-3

Gourbesville P (2009) Data and hydroinformatics: new possibilities and challenges. J Hydroinf 11(34):330-343. doi:10.2166/hydro. 2009.143

Guinot V, Soares-Frazão S (2006) Flux and source term discretization in two-dimensional shallow water models with porosity on unstructured grids. Int J Numer Method Fluid 50(3):309-345. doi:10.1002/fld.1059

Hinkelmann R (2005) Efficient numerical methods and informationprocessing techniques in environment water. Springer, Berlin

Hinkelmann R, Zehe E, Ehlers W, Joswig M (2011) Special section on landslides: setting the scene and outline of contributing studies. Vadose Zone J 10(2):473. doi:10.2136/vzj2011.0032

Horritt MS, Bates PD (2001) Effects of spatial resolution on a raster based model of flood flow. J Hydrol 253:239-249

Hou J, Liang Q, Simons F, Hinkelmann R (2013) A 2D well-balanced shallow flow model for unstructured grids with novel slope source term treatment. Adv Water Resour 52:107-131. doi:10. 1016/j.advwatres.2012.08.003

Hou J, Simons F, Hinkelmann R (2012) Improved total variation diminishing schemes for advection simulation on arbitrary grids. Int J Numer Method Fluid 70(3):359-382. doi:10.1002/fld.2700

Hou J, Simons F, Hinkelmann R (2013) A new TVD method for advection simulation on $2 \mathrm{D}$ unstructured grids. Int $\mathrm{J}$ Numer Method Fluid 71(10):1260-1281. doi:10.1002/fld.3709

Hou J, Simons F, Liang Q, Hinkelmann R (2014) An improved hydrostatic reconstruction method for shallow water model. J Hydraul Res. doi:10.1080/00221686.2013.858648
Hughes J, Decker J, Langevin C (2011) Use of upscaled elevation and surface roughness data in two-dimensional surface water models. Adv Water Resour 34(9):1151-1164. doi:10.1016/j.advwatres. 2011.02.004

Jain MK, Kothyari UC (2004) A GIS based distributed rainfall-runoff model. J Hydrol 299(1-2):107-135. doi:10.1016/j.jhydrol.2004. 04.024

Jain MK, Singh VP (2005) DEM-based modelling of surface runoff using diffusion wave equation. J Hydrol 302(1-4):107-126. doi:10.1016/j.jhydrol.2004.06.042

Kim B, Sanders BF, Schubert JE, Famiglietti JS (2014) Mesh type tradeoffs in 2D hydrodynamic modeling of flooding with a Godunov-based flow solver. Adv Water Resour 68:42-61. doi:10.1016/j.advwatres.2014.02.013

Lacasta A, Morales-Hernandez M, Murillo J, Garcia-Navarro P (2015) GPU implementation of the 2D shallow water equations for the simulation of rainfall/runoff events. Environ Earth Sci. doi:10.1007/s12665-015-4215-Z

Lawrence DSL (1997) Macroscale surface roughness and frictional resistance in overland flow. Earth Surf Process Landf 22:365-382

Liang D, Falconer RA, Lin B (2007) Coupling surface and subsurface flows in a depth averaged flood wave model. J Hydrol 337(1-2):147-158. doi:10.1016/j.jhydrol.2007.01.045

Liang Q, Marche F (2009) Numerical resolution of well-balanced shallow water equations with complex source terms. Adv Water Resour 32(6):873-884. doi:10.1016/j.advwatres.2009.02.010

McMillan HK, Brasington J (2007) Reduced complexity strategies for modelling urban floodplain inundation. Geomorphology 90(3-4):226-243. doi:10.1016/j.geomorph.2006.10.031

Morvan H, Knight D, Wright N, Tang X, Crossley A (2008) The concept of roughness in fluvial hydraulics and its formulation in 1D, 2D and 3D numerical simulation models. J Hydraul Res 46(2):191-208. doi:10.1080/00221686.2008.9521855

Mügler C, Planchon O, Patin J, Weill S, Silvera N, Richard P, Mouche E (2011) Comparison of roughness models to simulate overland flow and tracer transport experiments under simulated rainfall at plot scale. J Hydrol 402(1-2):25-40. doi:10.1016/j. jhydrol.2011.02.032

Néelz S, Pender G (2007) Sub-grid scale parameterisation of 2D hydrodynamic models of inundation in the urban area. Acta Geophys 56(3):65-72

Özgen I, Teuber K, Liang D, Hinkelmann R (2015) Surface roughness parameterization to account for subgrid scale topography in shallow water flow modeling. In: Proceedings of the 36th IAHR World Congress. The Hague, the Netherlands

Pradhan A, Kim YT (2015) Application and comparison of shallow landslide susceptibility models in weathered granite soil under extreme rainfall events. Environ Earth Sci 73(9):5761-5771. doi:10.1007/s12665-014-3829-x

Razafison U, Cordier S, Delestre O, Darboux F, Lucas C, James F (2012) A Shallow Water model for the numerical simulation of overland flow on surfaces with ridges and furrows. Eur J Mech B Fluid 31:44-52. doi:10.1016/j.euromechflu.2011.07.002

Simons F, Busse T, Hou J, Özgen I, Hinkelmann R (2014) A model for overland flow and associated processes within the Hydroinformatics Modelling System. J Hydroinf 16(2):375-391. doi:10. 2166/hydro.2013.173

Smith LS, Liang Q (2013) Towards a generalised GPU/CPU shallowflow modelling tool. Comput Fluid 88:334-343. doi:10.1016/j. compfluid.2013.09.018

Smith MW (2014) Roughness in the earth sciences. Earth Sci Rev 136:202-225. doi:10.1016/j.earscirev.2014.05.016

Smith MW, Cox NJ, Bracken LJ (2007) Applying flow resistance equations to overland flows. Progr Phys Geogr 31(4):363-387. doi:10.1177/0309133307081289 
Souchere V, King D, Daroussin J, Papy F, Capillon A (1998) Effects of tillage on runoff directions: consequences on runoff contributing area within agricultural catchments. J Hydrol 206(3-4):256-267. doi:10.1016/S0022-1694(98)00103-6

Stadler L, Hinkelmann R, Helmig R (2012) Modeling macroporous soils with a two-phase dual-permeability model. Transp Porous Media 95:585-601

Teuber K (2015) Development of a scaling approach to account for microtopography in the shallow water equations. Master thesis, Technische Universität Berlin

Thompson SE, Katul GG, Porporato A (2010) Role of microtopography in rainfall-runoff partitioning: an analysis using idealized geometry. Water Resour Res. doi:10.1029/2009WR008835

Toro EF, Spruce M, Speares W (1994) Restoration of the contact surface in the HLL-Riemann solver. Shock Waves 4(1):25-34. doi:10.1007/BF01414629

Tsihrintzis VA, Wu FC, Shen HW, Chou YJ (2001) Discussion and closure: variation of roughness coefficients for unsubmerged and submerged vegetation. J Hydraul Eng 127(3):241-245

Volp ND, van Prooijen BC, Stelling GS (2013) A finite volume approach for shallow water flow accounting for high-resolution bathymetry and roughness data. Water Resour Res 49(7):4126-4135. doi:10.1002/wrcr.20324

van der Walt S, Colbert CS, Varoquaux G (2011) The NumPy array: a structure for efficient numerical computation. Comput Sci Eng $13: 22-30$

Yörük A (2009) Unsicherheiten bei der hydrodynamischen Modellierung von Überschwemmungsgebieten, Mitteilungen / Institut für Wasserwesen, vol 99. Universität der Bundeswehr München

Yu D, Lane SN (2006) Urban fluvial flood modelling using a twodimensional diffusion-wave treatment, part 1: mesh resolution effects. Hydrol Process 20(7):1541-1565. doi:10.1002/hyp.5935

Zhao M, Yue T, Zhao N, Yang X, Wang Y, Zhang X (2015) Parallel algorithm of a modified surface modeling method and its application in digital elevation model construction. Environ Earth Sci. doi:10.1007/s12665-015-4177-1

Zhu C, Byrd RH, Nocedal J (1997) L-BFGS-B: Algorithm 778: L-BFGS-B, FORTRAN routines for large scale bound constrained optimization. ACM Trans Math Softw 23(4):550-560 